\title{
Infection of Cytomegalovirus in Cholestasis Infant with Biliary Atresia
}

\author{
Lasmauli Situmorang, ${ }^{1}$ Bagus Setyoboedi, ${ }^{1}$ Gondo Mastutik, ${ }^{2}$ Sjamsul Arief ${ }^{1}$ \\ ${ }^{1}$ Division of Hepatology, Department of Child Health, Faculty of Medicine, Airlangga University/Dr. Soetomo Hospital, Surabaya, Indonesia. \\ E-mail:baguzze@gmail.com \\ ${ }^{2}$ Department of Anatomic Pathology, Faculty of Medicine, Airlangga University/Dr. Soetomo Hospital, Surabaya, Indonesia
}

\begin{abstract}
Biliary Atresia (BA) is extrahepatic cholestasis that results in death within the first two years if the diagnosis and intervention are delayed. The etiology and pathogenesis of BA are still undetermined. Viral infections, including Cytomegalovirus (CMV), are presumed to be one of the causes. Cytomegalovirus infection is more common in intrahepatic than extrahepatic cholestasis such as BA. There are limited data about Cytomegalovirus infection in cholestatic infants with BA. This study compared the incidence of CMV infection in cholestatic infants with biliary atresia and non-biliary atresia. A cross-sectional study was performed in December 2017 - August 2018 in cholestatic infants aged 1-6 months. Liver biopsy, histopathological examination followed by PCR CMV examination were performed on cholestatic infants. The results of the PCR examination were compared between BA and non-BA infants. Statistical analysis of Chi-Square, t-test independent and Mann-Whitney $U$ resulting in $p<0.05$ were stated as significant. Thirty-seven children were obtained during the study period, consisting of sixteen children with BA and twenty-one children with non-BA. Biliary atresia was predominantly found in female than male children, despite no differences were found between the groups $(p=0.163)$. There were differences in body weight $(p=0.002)$ age $(p=0.009)$, birth weight $(p=0.02)$ and gestational age $(p=0.03)$ between children with BA and non-BA. There was no significant difference in the incidence of CMV infection in cholestatic infants with $B A$ and non-BA $(p=0.338)$. Cytomegalovirus infection in cholestatic infants with BA was less than non-BA cholestatic infants.
\end{abstract}

Keywords: Biliary atresia, cholestasis, cytomegalovirus, polymerase chain reaction

\section{INTRODUCTION}

Biliary Atresia $(\mathrm{BA})$ remains a great challenge for clinicians because it has poor clinical outcomes if not early diagnosed and intervened. ${ }^{1,2}$ Biliary atresia is a type of extrahepatic cholestasis which is frequently found in infants. However; the etiology and pathogenesis of BA are still undetermined. Particular viruses have been suggested to play a role in pathogenesis BA, including group C Rotavirus, Reovirus and Cytomegalovirus (CMV). ${ }^{3}$

Cytomegalovirus infection is often found in intrahepatic cholestasis; however, currently, there are several studies which showed CMV infection in extrahepatic cholestasis, including BA. ${ }^{4,5}$ Cholestasis is classified as intrahepatic and extrahepatic cholestasis, and there are several methods for diagnosing CMV infection, including Polymerase Chain Reaction (PCR). There is no single examination that is $100 \%$ accurate in diagnosing CMV infection. Polymerase Chain Reaction examination can use blood, urine and tissue specimens, which are ideally carried out at the age of three weeks after birth. ${ }^{6}$ The PCR examination cannot be performed at the age of three weeks because most cases of CMV infection are asymptomatic and high in cost; however, PCR can detect viral DNA with low amounts of sample and time-efficient. $^{7}$

The gold standard of diagnosis of BA is intraoperative cholangiography; however, liver biopsy and following histopathological examination have quite high sensitivity of approximately $96.9 \%{ }^{8}$ Several studies showed positive CMV results in PCR examination of liver biopsies of patients with $A B .{ }^{9,10}$ However, there is no data on the incidence of CMV infection in cholestatic infants with BA in Dr. Soetomo Hospital, Surabaya. Therefore, a preliminary study is needed to determine the incidence of CMV infection in cholestatic patients with $B A$ and without BA by using PCR in liver tissue in Dr. Soetomo Hospital, Surabaya.

\section{METHODS}

A cross-sectional study was performed from December 2017 to August 2018. Cholestasis infants aged 1-6 months old who were treated at Hepatology division were included. Cholestasis infants associated with severe infections (sepsis) or 
severe multi-organ abnormalities, a history of ganciclovir treatment, and immunodeficient patients were excluded. Each subject underwent a laboratory test (complete blood count, total bilirubin, direct bilirubin, AST, ALT, albumin) and liver tissue biopsy conducted by the Pediatric Hepatology consultant. Biopsy of liver tissue was stored in a tube then sent to the Pathology Department of Dr. Soetomo Hospital Surabaya and Tropical Disease Airlangga University. The study protocol was approved by the Ethical Commission of Health Research of Dr. Soetomo Hospital with number No.729/Panke.KKE/XII/2017.

Polymerase chain reaction examination was carried out by extracting DNA using QIAampDNA Mini Kit (Qiagen) from a liver biopsy and based on manual according to the kit. Beta-globin genes were identified using $\mathrm{PCO}+$ and $\mathrm{PCO} 4+$ primers with the ability to produce $110 \mathrm{bp}$ products with certain sequences (Table 1). Cytomegalovirus was identified by nested PCR with primer MIE4 and MIE5 for first-cycle which produced 435bp; while IE1 and IE2 products were used for the second cycle which produced $161 \mathrm{bp}$.

Polymerization chain reaction mixtures required for $\beta$ globin were mastermix (Promega): $10 \mu \mathrm{L} /$ reaction, FWD primer (PCO3 +) 10pmol: $1 \mu \mathrm{L} /$ reaction, primary REV $(\mathrm{PCO} 4+)$ 10pmol: $1 \mu \mathrm{L} /$ reaction, $\mathrm{ddH} 2 \mathrm{O}$ (water): $5 \mu \mathrm{L} /$ reaction, DNA template: $3 \mu \mathrm{L} /$ reaction, with $\mathrm{PCR}$ conditions as follows: initial denaturation at $94^{\circ} \mathrm{C}$ for 5 minutes, denaturation at $94^{\circ} \mathrm{C}$ for $30 \mathrm{sec}$, annealing at $55^{\circ} \mathrm{C}$ for 30 seconds, elongation at $72^{\circ} \mathrm{C}$ for 45 seconds, final elongation at $72^{\circ} \mathrm{C}$ for 7 minutes. All of this process was performed 40 cycles.

Four microliters were taken from first-cycle products for second-cycle PCR. Polymerase chain reaction mixture in second-cycle was the same as first-cycle, the differences were only in the product used. The PCR product was visualized by electrophoresis in $2 \%$ agarose gel, stained with ethidium bromide, and viewed under ultraviolet light.

Data were collected and presented as a written explanation, tabulation, and diagrams. Descriptive analysis was used to calculate the number of $B A$ and non-BA cases, the number of CMV infection in BA and non-BA cholestatic infants, and compare the number of CMV infection between BA and BA patients with the Chi-Square test.

\section{RESULTS AND DISCUSSION}

There were 37 cholestasis infants involved in this study, dominated by 21 male infants an average age of 2.9 (SD 1.28) months and an average body weight of 4632 (SD 1070) gram. Most patients live outside of Surabaya. Table 2 showed the basic characteristics of pediatric patients with cholestasis. It can be seen that the number of cholestatic infants with BA was smaller (43.2\%) compared to without BA (56.8\%).

Table 2. Baseline characteristic of cholestasis infant

\begin{tabular}{lc}
\hline Characteristic & \\
\hline Age, mean ( \pm SD) & $2.9( \pm 1.28)$ \\
Age, $\mathbf{n}(\%)$ & \\
1 month & $4(10.8)$ \\
2 month & $14(37.9)$ \\
3 month & $7(18.9)$ \\
4 month & $6(16.2)$ \\
5 month & $6(16.2)$ \\
6 month & $0(0)$ \\
Birth weight, mean $( \pm$ SD) & $4632,4( \pm 1070,06)$ \\
Gender (\%) & \\
$\quad$ Girl & $16(43.2)$ \\
Boy & $21(56.8)$ \\
Gestationalage, $\mathbf{n}(\%)$ & \\
Aterm & $25(67.62)$ \\
Preterm & $12(32.4)$ \\
Type of cholestasis, $\mathbf{n}(\%)$ & \\
Biliary atresia & $16(43.2)$ \\
Non-biliary atresia & $21(56.8)$ \\
Residence, $\mathbf{n}$ (\%) & \\
Surabaya & $11(29.7)$ \\
Outside of Surabaya & $26(70.3)$ \\
\hline
\end{tabular}

Table 1. The primer used with the sequence and its product

\begin{tabular}{lrc}
\hline Primer & \multicolumn{1}{c}{ Sequence } & Product \\
\hline MIE4 & 5'-CCA AGC GGC CTC TGA TAA CCA AGC C-3' & $435 \mathrm{bp}$ \\
MIE5 & 5'-CAG CAC CAT CCT CCT CTT CCT CTG G-3' & $435 \mathrm{bp}$ \\
IE1 & 5'- CCA CCC GTG GTG CCA GCT CC-3' & 161bp \\
IE2 & 5'-CCC GCT CCT CCT GAG GAC CC-3' & 161bp \\
PC03+ & 5'-CCT CTG ACA CAA CTG TGT TCA CTA GC-3' & 110bp \\
PC04+ & 5'-TCA CCA CCA ACT TCA TCC ACG TTC ACC-3' & 110bp \\
\hline
\end{tabular}


This study aimed to compare the incidence of CMV infection in BA and non-BA cholestatic infants. In addition to clinical manifestation, histopathological examination of liver tissue biopsy was used to distinguish between BA and non-BA cholestatic infants. ${ }^{11}$ Biliary atresia is typically characterized by biliary duct proliferation, bile plugs, and portal tract edema/fibrosis in biopsy liver. A study showed that liver biopsy had a sensitivity, specificity, and accuracy of $88.2 \%{ }^{12}$ Similar to study by Lee and Looi, biliary duct proliferation in BA showed $95 \%$ sensitivity and $88 \%$ specificity, while bile plugs showed $68 \%$ sensitivity and $86 \%$ specificity. ${ }^{13}$ Russo et al. found significant differences between $B A$ and non-BA, indicated by more severe biliary duct proliferation, bile plugs in the ductus and canaliculi and portal fibrosis in BA cases. ${ }^{14}$

In this study, BA cases were predominantly found in female infants compared to male infants. Contrastingly, non-BA cases in male infants were higher compared to female infants. There were significant differences in body weight, age, birth weight and gestational age (Table 3 ).

The study by Bellomo-Brandao et al. found that from 165 infants, intrahepatic cholestasis was found in $62.64 \%$ male infants, while extrahepatic cholestasis was found in $55.25 \%$ female infants with $p$-value $=0.026 .15$ This finding was similar to this study; despite no significant differences were found, this study showed that BA or extrahepatic cholestasis was commonly found in female infants.

This study showed significant differences in birth weight between BA and non-BAcholestatic infants. The birth weight of $B A$ infants was greater than non-BA infants, indicated by birth weight $>2500$ grams was more commonly found in BA infants. This finding was similar to previous research suggesting that higher body weight and greater length at birth were found in children with extrahepatic cholestasis. ${ }^{15}$ A study by Fischler et al.

Table 3. Characteristics of BA and non-BA infants

\begin{tabular}{|c|c|c|c|}
\hline Characteristic & $\begin{array}{l}\text { Biliary Atresia } \\
\text { (BA) }(n=16)\end{array}$ & $\begin{array}{l}\text { Non-Biliary Atresia } \\
\text { (Non-BA) }(n=21)\end{array}$ & $\mathbf{P}$ \\
\hline \multicolumn{4}{|l|}{ Age, n (\%) } \\
\hline Boy & $7(33.3)$ & $14(66.7)$ & 0 \\
\hline Girl & $9(56.3)$ & $7(33.7)$ & $0.163^{*}$ \\
\hline Birth weight, mean $( \pm$ SD) & $5218.7( \pm 926.08)$ & $4185( \pm 966.07)$ & \\
\hline Age (month), mean $( \pm S D)$ & $3.5( \pm 1.15)$ & $2.43( \pm 1.21)$ & $0.002^{* *}$ \\
\hline \multicolumn{4}{|l|}{ Age (month), $n$ (\%) } \\
\hline One & $0(0)$ & $4(100.0)$ & $0.009^{\star * *}$ \\
\hline Two & $4(28.6)$ & $10(71.4)$ & \\
\hline Three & $4(57.1)$ & $3(42.9)$ & \\
\hline Four & $4(66.7)$ & $2(33.3)$ & \\
\hline Five & $4(66.7)$ & $2(33.3)$ & $0.111^{*}$ \\
\hline \multicolumn{4}{|l|}{ Gestational age, n (\%) } \\
\hline Aterm & $15(60.0)$ & $10(40.0)$ & \\
\hline Preterm & $1(8.3)$ & $11(91.7)$ & $0.003^{*}$ \\
\hline Birth weight, & 2953.1 & 2542.4 & \\
\hline Mean $( \pm$ SD) & $( \pm 295.22)$ & $( \pm 684.16)$ & $0.020^{\star \star}$ \\
\hline \multicolumn{4}{|l|}{ Birth weight, n (\%) } \\
\hline$<2500$ & $1(9.1)$ & $10(90.9)$ & \\
\hline$>2500$ & $15(57.7)$ & $11(42.3)$ & $0.006^{*}$ \\
\hline \multicolumn{4}{|l|}{ IgM CMV n (\%) } \\
\hline Positive & $9(69.2)$ & $4(30.8)$ & 0 \\
\hline Negative & $7(29.2)$ & $17(70.8)$ & $.019 *$ \\
\hline \multicolumn{4}{|l|}{ IgG CMV n (\%) } \\
\hline Positive & $15(45.5)$ & $18(54.5)$ & $0.435^{\star}$ \\
\hline Negative & $1(25.0)$ & $3(75)$ & \\
\hline
\end{tabular}

$\mathrm{SD}=$ Standard Deviation ${ }^{*}$ Chi-Square, $\quad$ ** independent t-test, *** Mann-Whitney U 
found that preterm birth was superior in children with BA 3/30 (10\%) compared to those without BA $5 / 55$ (9\%). However, this difference was not significant. Also, this study found that preterm birth was more frequently found in non-BA infants. ${ }^{16}$

The older age was found in BA infants compared to non-BA infants when patients were admitted to the hospital. This was different from the previous study which found that older infants were found in cholestatic patients without BA, supported by other studies which found that there were no significant differences between both groups. ${ }^{15,16}$

There were nostatistically significant differences in the onset of jaundice between cholestatic infants with $B A$ and without $B A$, the onset of the yellow appearance of BA infants was longer than non-BA infants (Table 4).This was a contrast to previous studies which found the remarkably quick onset of jaundice in patients with BA. ${ }^{17}$ The difference of the onset of jaundice in these two groups could have been different based on parents' perspective and knowledge. Parents/families sometimes do not know that the children have pathologic icteric and patients with BA still show good nutritional status at the onset of the disease.

On laboratory examination, significant differences in leukocytes count were found between the two groups (Table 4); whereas there were no significant differences in laboratory results, such as complete blood count (hemoglobin, platelets), liver function (ALT/AST), albumin, direct bilirubin, and total bilirubin levels. Higher leukocyte count was found in patients with BA and in accordance with these findings, Wibowo reported comparable

Table 4. Clinical manifestation of BA and non-BA infants

\begin{tabular}{|c|c|c|c|}
\hline \multirow{2}{*}{ Clinical manifestation } & \multicolumn{2}{|c|}{ Mean ( \pm SD) } & \multirow{2}{*}{$\mathbf{p}$} \\
\hline & Biliary atresia & Non-biliary atresia & \\
\hline Onset of jaundice & $3.4( \pm 0.44)$ & $3.7( \pm 0.39)$ & $0.259^{\star \star}$ \\
\hline Direct bilirubin & $31.4( \pm 26.62)$ & $25.1( \pm 29.29)$ & $0.646^{*}$ \\
\hline Total bilirubin & $9.1( \pm 4.59)$ & $9.6( \pm 4.86)$ & $0.968^{* *}$ \\
\hline Hemoglobin & $8.4( \pm 6.2)$ & $8.5( \pm 6.11)$ & $0.963^{* *}$ \\
\hline Leukocyte & $10.5( \pm 2.07)$ & $11.2( \pm 2.88)$ & $0.034^{\star *}$ \\
\hline Platelet & $14640( \pm 5844)$ & 10469 (3682) & $0.304^{*}$ \\
\hline AST & $355.583( \pm 145.052)$ & 371.444 (156.949) & $0.63^{* *}$ \\
\hline ALT & $246.2( \pm 95.39)$ & $215.8( \pm 161.66)$ & $0.101^{\star \star}$ \\
\hline Albumin & $213.9( \pm 133.73)$ & $164.9( \pm 114.27)$ & $0.063^{*}$ \\
\hline
\end{tabular}
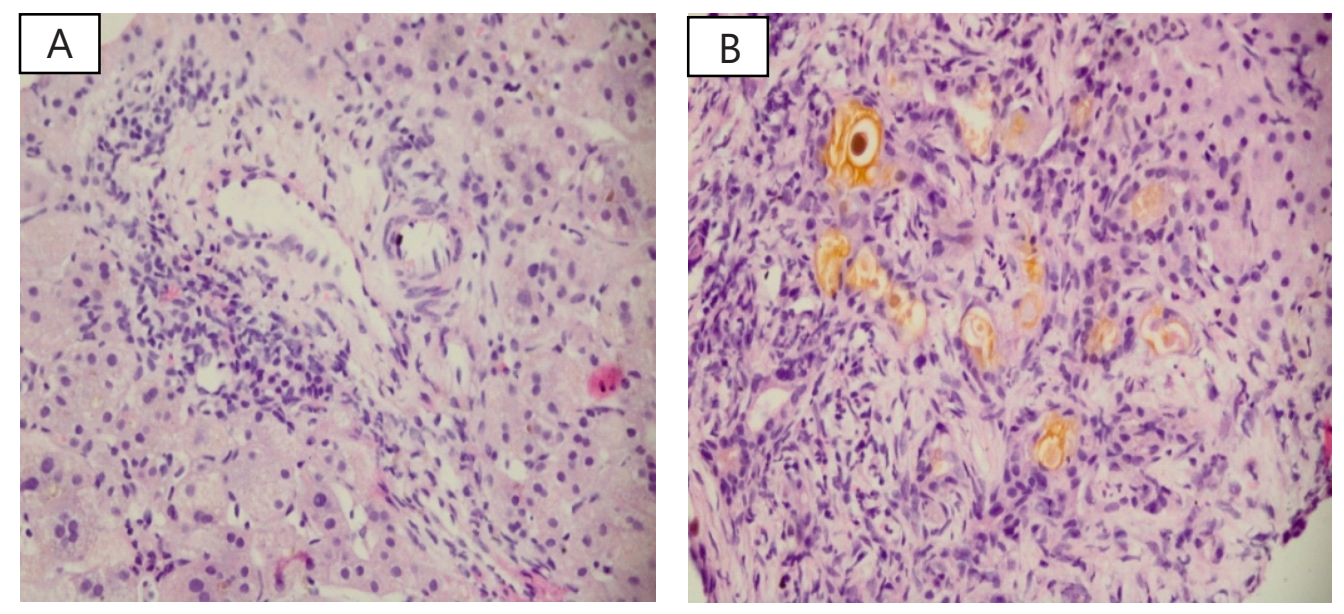

Figure 1. Histopathological features of liver tissue biopsy with a 400x magnification of a microscope. Figure A shows a picture of the portal track of intrahepatic cholestasis as indicated by the presence of giant cell hepatitis (red arrow) and no bile duct proliferation. Figure B shows a picture of BA (extrahepatic cholestasis) as biliary ducts proliferation that contains a bile plug (blue arrow) in the portal tract. 

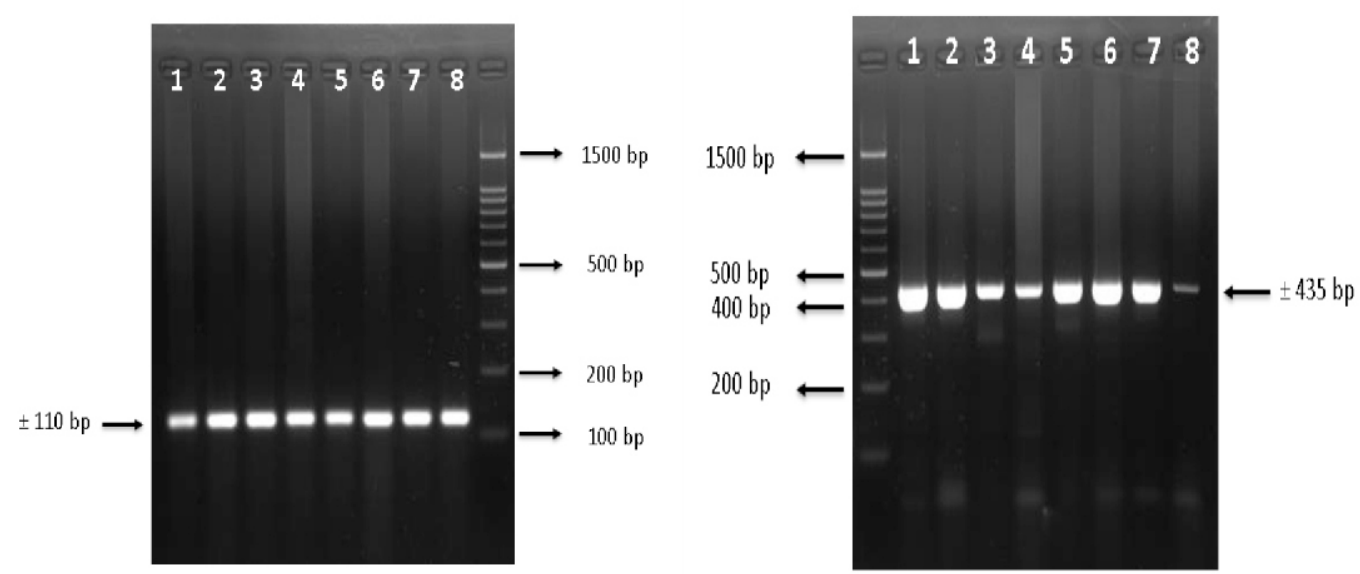

Figure 2. (A) Electrophoresis of $\beta$ globin $\mathrm{PCR}$ gene using $\mathrm{PCO} 3$ and $\mathrm{PCO} 4$ primers (in 8 samples) which produced 110bp products followed by (B) electrophoresis PCR results using primers MIE4 and MIE5 which produced $435 \mathrm{bp}$

Table 5. Comparison of $C M V$ infection in cholestatic infants with $B A$ and without $B A$ based on the results of PCR in liver tissue

\begin{tabular}{cccc}
\hline Liver Biopsy PCR CMV, n (\%) & Biliary Atresia & Non-Biliary Atresia & p \\
\hline Positive & $9(37.5)$ & $15(62.5)$ & $0.338^{*}$ \\
Negative & $7(53.8)$ & $6(46.2)$ & \\
\hline
\end{tabular}

results, although the increase in leukocytes in BA remained unexplained. ${ }^{18}$

The diagnosis of BA was based on clinical manifestations (yellowing of the eyes and whole body, a cholic stool) and anatomical pathology examination (histopathological features such as bile plug, ductular proliferation, and portal edema with and/or fibrosis of liver biopsy tissue (Figure 1).

Biopsy samples were taken and extracted from liver tissue, then PCR was carried out with $\beta$ globin using $\mathrm{PCO} 3$ primers to determine the quality of the samples. If a positive result (yielding a product of $100-200 \mathrm{bp}$ ) is obtained, the examination must be continued by PCR examination using primers MIE4 and MIE5. A positive result is reported if the product produces $400-500 \mathrm{bp}$. In this study, positive results were obtained for all $\beta$ globin effects; therefore, PCR was performed (Figures 2).

The detection of CMV by PCR showed positive results in 24 infants and negative results in 13 patients. The incidence of CMV infection in cholestatic infants with BA and without BA was $56.2 \%$ and $71.4 \%$, respectively. The polymerase chain reaction is a diagnostic instrument that has high sensitivity and ability to detect the presence of CMV, despite low specificity and low CMV infection. ${ }^{19}$

Cytomegalovirus infection is initially more common in intrahepatic cholestasis (without BA); however, several studies have shown that CMV infection can be found in extrahepatic cholestasis (BA). The study found that viruses including CMV can be a trigger leading to dysregulation of immune mechanisms with genetic influences and eventually cause BA. ${ }^{20}$ Cytomegalovirus infection has the ability to replicate both in hepatocytes and cholangiocytes. This virus can directly induce damage to the liver and biliary duct system and induce damage to the immune system in infected cells, leading to the formation of inclusion of bodies in hepatocyte and vascular cells of epithelial cells, especially along with biliary duct epithelial cells. ${ }^{21}$

There were no significant differences between $B A$ and non-BA cholestatic infants based on the PCR of CMV in liver tissue (Table 5). This study showed that positive PCR results of CMV were only found in 9 (37.5\%) BA patients. The study about PCR CMV was begun by conducting several studies on animals, and subsequently was carried out on humans. ${ }^{22-25}$ In this study, there were no significant differences in the number of CMV infection in infants with $B A$ and without BA. This was because BA could be caused by other viruses such as Rotavirus, Reovirus, Ebstein-Barr Virus (3.5\%) and Adenovirus (5.8\%). ${ }^{26,27,9}$ Presumed role of Rotavirus and Reovirus in BA have also been studied for a long time.

Fjaer et al. found 4 cases of CMV infection from a 
total of 9 cholestatic patients. However, positive PCR of CMV from liver tissue was only found in 2 patients from 4 cases of CMV infection. Cytomegalovirus infection in the other 2 patients was caused by Ebstein-Barr Virus. ${ }^{28}$ The presence of the Human Herpes virus 6 in liver tissue was also demonstrated by Domiati et al. in their study about Human Herpes six virus in BA patients. Cytomegalovirus infection; however, was not found in the study subjects or controls. $^{29}$

\section{CONCLUSION AND SUGGESTION}

Cytomegalovirus infection is found in intrahepatic and extrahepatic cholestatic infants like BA. In this study, the lower incidence of CMV infection in cholestatic infants with BA was found compared to non-BA. However, there was no significant difference in the incidence of CMV infection in cholestatic infants with BA or without BA. Future research with longer research time and PCR was needed to determine the causal virus of BA.

\section{REFERENCES}

1. Santos JL, Carvalho E, Bezerra JA. Advances in biliary atresia: From patient care to research. Braz. J. Med. Biol, Res. 2010; 43(6): 522-527.

2. Bassett MD, Murray KF. Biliary atresia: Recent progress. J. Clin. Gastroenterol, 2008; 42(6): 720-729.

3. Moreira RK, Cabral R, Cowles RA, Lobritto SJ. Biliary atresia: A multi disciplinary approach to diagnosis and management. Arch. Pathol. Lab. Med, 2012; 136(7): 746-760.

4. Sira MM, Salem TAH, Sira AM. Biliary atresia: A challenging diagnosis. Global Journal of Gastroenterology, 2013; 1:24-35.

5. Oliveira NL, Kanawaty FR, Costa SC, Hessel G. Infection by Cytomegalovirus in patients with neonatal cholestasis. Arq. Gastroenterol, 2002; 39(2): 132-136.

6. Buonsenso D, Serranti D, Gargiullo L, Ceccarelli M, Ranno O, Valentini P. Congenital Cytomegalovirus infection: Current strategies and future perspectives. Eur Rev Med Pharmacol Sci, 2012; 16(17): 919-935.

7. Caliendo AM, Schuurman R, Yen-Lieberman B, Spector SA, Andersen J, et al. Comparison of quantitative and qualitative $P C R$ assays for Cytomegalovirus DNA in plasma. J Clin Microbiol, 2001; 39(4): 1334-1338.

8. Mack CL, RJ Sokol. Unraveling the pathogenesis and etiology of biliary atresia. Pediatr Res, 2005; 57: 87-94.

9. XuY, YuJ, ZhangR, Yin Y, Ye J, et al. The perinatal infection of Cytomegalovirus is an important etiology for biliary atresia in China. Clin. Pediatr (Phila), 2012; 51(2): 109-113.

10. Rauschenfels $\mathrm{S}$, Krassmann M, Al-Masri AN, Verhagen $\mathrm{W}$, Leonhardt J, et al. Incidence of hepatotropic viruses in biliary atresia. Eur.J. Pediatr, 2009; 168(4): 469-476.

11. Rashed YK, Saber MA, Tawfik M, Mourad WS. Histopathological features and accuracy for diagnosing biliary atresia by prelaparotomy liver biopsy in Egypt. Egyptian. Pediatric Association Gazette, 2013; 61: 42-45.

12. Rastogi AN, Krishnani K, Yachha V, Khanna U, Poddar, et al. Histopathological features and accuracy for diagnosing biliary atresia by prelaparotomy liver biopsy in developing countries. J. Gastroenterol Hepatol, 2009; 24(1): 97-102.

13. Lee WS, Looi LM. Usefulness of a scoring system in the interpretation of histology in neonatal cholestasis. World J.Gastroenterol, 2009; 15(42): 5326-5333.

14. Russo P, Magee JC, Boitnott J, Bove KE, Raghunathan $\mathrm{T}$, et al. Design and validation of the biliary atresia research consortium histologic assessment system for cholestasis in infancy. Clinical Gastroenterology and Hepatology: American Gastroenterological Association, 2011; 9(4): 357-362.

15. Bellomo-Brandao MA, Arnaut LT, Tommaso AM, Hessel G. Differential diagnosis of neonatal cholestasis: Clinical and laboratory parameters. J. Pediatr, 2010; 86(1): 40-44.

16. Fischler B, Woxenius $S$, Nemeth A, Papadogiannakis $\mathrm{N}$. Immunoglobulin deposits in liver tissue from infants with biliary atresia and the correlation to cytomegalovirus infection. J. Pediatr. Surg, 2005; 40(3): 541-546.

17. Bazlul Karim AS, Kamal M. Cholestasis jaundice during infancy: experience at a tertiary-care center in Bangladesh. Indian. J. Gastroenterol, 2005; 24(2): 52-54.

18. Wibowo S, Santoso NB. Karakteristik klinik dan laboratorik kolestasis intrahepatal dan ekstrahepatal di bangsal perawatan anak RSU Dr. Saiful Anwar Malang. M. Med. Indones, 2012; 46(2): 108-114.

19. Jahan M. Laboratory diagnosis of $C M V$ infection: $A$ review. Bangladesh J. Med. Microbiol, 2010; 4(2): 39-44.

20. Mack CL. The pathogenesis of biliary atresia: Evidence for a virus-induced autoimmune disease. Semin. Liver Dis, 2007; 27(3): 233-242.

21. Lazim HH, Kadhim HS, Arif $\mathrm{H}$, Al Khafaji KR. The association between biliary atresia and Cytomegalovirus hepatitis. J.Nepal Paediatr. Soc, 2015; 35(3): 269-274.

22. Wang W, Zheng S, Shong Z, Zhao R. Developmental of a guinea pig model of perinatal Cytomegalovirus induced hepatobiliary injury. Fetal. Pediatr. Pathol, 2011; 30(5): 301-311.

23. Wang W, Donnelly B, Bondoc A. The rhesus rotavirus gene encoding VP4 is a major determinant in the pathogenesis of biliary atresia in newborn mice. J. Virol, 2011; 85(17): 9069-9077.

24. Soomro GB, Abbas Z, Hassan M, Luck N, Memon $Y$, Khan AW. Is there any association of extrahepatic biliary atresia with cytomegalovirus or other 
infections?. J. Pak. Med. Assoc, 2011;61(3): 281-283.

25. Yaghobi R, Didari M, Gramizadeh B. Study of viral infections in infants with biliary atresia. Indian J. Pediatr, 2011; 78(4): 478-481.

26. Von Sochaczewski CO, Pintelon I, Brouns I, Dreier A, Klemann C, et al. Rotavirus particles in the extrahepatic bile duct in experimental biliary atresia. J. Pediatr. Surg, 2014; 49(4): 520-524.

27. Tyler KL, RJ Sokol, SM Oberhaus. Detection of reovirus RNA in hepatobiliary tissues from patients with extrahepatic biliary atresia and choledochal cysts. Hepatology, 1998; 27(6): 1475-1482.

28. Fjaer RB, Bruu AL, Nordbo. Extrahepatic bile duct atresia and viral involvement. Pediatr. Transplant, 2005; 9(1): 68-73.

29. Domiati-Saad R, Dawson DB, Margraf LR. Cytomegalovirus and human herpesvirus 6 , but not human papillomavirus, are present in neonatal giant cell hepatitis and extrahepatic biliary atresia. Pediatr. Dev. Pathol, 2000; 3(4): 367-373. 